\title{
A method to identify the variable ecosystem services relationship across time: a case study on Yanhe Basin, China
}

\author{
Zhenmin Zheng $\cdot$ Bojie Fu $\cdot$ Haitang Hu \\ Ge Sun
}

Received: 3 January 2014 / Accepted: 30 August 2014/Published online: 2 October 2014

(C) Springer Science+Business Media Dordrecht 2014

\begin{abstract}
Ecosystem services are increasingly recognized as the foundations of a well-functioning society. Large-scale ecological restoration projects have been implemented around China with the goal of restoring and sustaining ecosystem services, especially in vulnerable semi-arid regions where soil and water resources are most stressed due to historic human activities. The relationships among ecosystem services are often driven by land-use changes. It is necessary to develop an applicable method to explore the relationships between ecosystem services and driving factors over time. We selected the Yanhe Basin on China's Loess Plateau as the study area, which has experienced a large-scale Grain for Green Project (GGP), and quantified four ecosystem services (soil conservation, water retention, water yield, and crop production). The results of this study show that different trends have
\end{abstract}

Electronic supplementary material The online version of this article (doi:10.1007/s10980-014-0088-x) contains supplementary material, which is available to authorized users.

Z. Zheng · B. Fu $(\bowtie) \cdot H$. Hu

State Key Laboratory of Urban and Regional Ecology, Research Center for Eco-Environmental Sciences, Chinese Academy of Sciences, Beijing 100085, China e-mail: bfu@rcees.ac.cn

G. Sun

Eastern Forest Environmental Threat Assessment Center, Southern Research Station, USDA Forest Service, 920 Main Campus Dr., Venture 2, Suite 300, Raleigh, NC 27606, USA occurred for ecosystem services during 2000-2008. We found potential tradeoffs between soil conservation and water yield. Synergies may exist among water retention and soil conservation/water yield. Two types of preconditions were pointed out in the analysis process to define the potential relationships among ecosystem service variables. The correspondence analysis was used to explore its intrinsic linkage and its variations among ecosystem services, land uses, and spatial locations. It suggests that the intensities of the ecosystem services provided by most of land uses and the internal proportion of regulating service to provision service in a sub-basin has been changed by GGP, but the relative spatial patterns of ecosystem services are still being maintained in entire basin scale from 1980 to 2008.

Keywords Grain for Green Project · Land use · Subbasin $\cdot$ Ecosystem services $\cdot$ Correspondence analysis

\section{Introduction}

Ecosystem services connect the human society with natural systems (Costanza et al. 1997; Daily 1997). In order to improve regional ecosystem services, some countries have carried out large-scale ecological restoration projects (Fu et al. 2011; Rodrigues et al. 2011), but not all ecosystem services have been 
enhanced during the implementation of the project $(\mathrm{Lu}$ et al. 2012). In different regions, the results differ for various ecosystem services. It is necessary to identify the relationship between ecosystem services and spatial variability of ecosystem services under the process of ecological restoration. Changes in land use play important roles in the degradation of ecosystem services (Martinez et al. 2009; Bryan 2013), but they are also primary means for improving ecosystem services, especially for large-scale projects (Goldstein et al. 2012). Therefore, quantifying the linkages between the land-use types and the corresponding ecosystem services is conducive to the further understanding of the mechanisms of ecosystem service improvement (Foley et al. 2005) and, therefore, it provides useful guidance for future ecological restoration projects (Daily et al. 2009).

Due to the arid climate (low precipitation and high evaporative potential), the ecosystems in semi-arid areas are particularly vulnerable to human disturbances (Cowie et al. 2011) and are limited when providing water-based ecosystem services such as water supplies to people. Because of climate change, human activities, steep terrains, and sparse vegetation (Su et al. 2012) in the semi-arid areas of the Loess Plateau, serious soil erosion has occurred. Tradeoffs between ecosystem provision services (crop production) and regulating services (soil conservation, water retention) have existed for a long time (Power 2010). Since 1999, the Chinese government has implemented a large-scale ecological restoration project, the Grain for Green Project (GGP), to control loss of soil and water (Chen et al. 2007). Past studies have suggested that various ecosystem services have changed under the GGP, but the degrees and directions of changes are not consistent; therefore, it is important to understand the relationships between ecosystem services (Nelson et al. 2009), land-use changes, and corresponding ecosystem services as well as the spatial locations and the specific ecosystem services. Although there are many articles that investigate the relationship between land use and ecosystem services, few articles describe the change of the relationship between the two over time, in a particularly clear and simple way. Discussion on the relationship between the spatial position and ecosystem services is useful for understanding the land-use change and ecosystem services.

At the landscape scale, the continuously increased vegetation coverage by the GGP significantly improved the abilities of regulatory ecosystem services and reduced the supply of crop production (Cao et al. 2009). The relationship between ecosystem services appears as either a tradeoff or as synergy. The main goal for landscape management is to enhance the synergy and weaken the tradeoffs between ecosystem services (Tallis et al. 2008; Nelson et al. 2009). Hence, the method for qualitative and quantitative analysis would be critical to optimizing the landscape ecosystem services. The correlation analysis is often used to determine the relationship between ecosystem services (Su and Fu 2013; Wu et al. 2013), but the correlation coefficients have different meanings when correlation occurs between spatial patterns and between dynamic changes for ecosystem services. The main purpose of this study is to develop an applicable methodology that can be used to analyze the variation of relationships between ecosystem services and both land use and spatial location over time.

\section{Data and methods}

Study area

Here, we selected the Yanhe Basin (E108 $45^{\prime}-$ $110^{\circ} 28^{\prime}, \mathrm{N} 36^{\circ} 23^{\prime}-37^{\circ} 17^{\prime}$ ) in Shaanxi Province in northwestern China as our study area. The Yanhe River is a first-order tributary of the Yellow River. The river has a length of $286.9 \mathrm{~km}$ and a drainage density of about $4.7 \mathrm{~km} / \mathrm{km}^{2}$, with an average gradient of $4.3 \%$. The total watershed area of the Yanhe Basin is $7,725 \mathrm{~km}^{2}$, with the loess hilly area accounting for $90 \%$ of the total basin area. The region is classified as a forest steppe zone and has suffered from serious soil erosion over the past 100 years. For the entire basin, the average annual precipitation is $496 \mathrm{~mm}$ with an annual average temperature ranging from 8.8 to $10.2{ }^{\circ} \mathrm{C}$. Drought, frost, hail, and heavy rains are the main types of meteorological disasters in the region.

\section{Methods}

Using biophysical models, we assess the physical quantities for four key ecosystem services including soil conservation, water retention, water yield, and crop production in the Yanhe Basin. We estimated the spatial correlations between any two kinds of 
ecosystem services. Through correspondence analysis, we reveal the connection between land use and the associated ecosystem services and we also explore the relevance of upstream and downstream with specific ecosystem services.

Based on three land-use maps of 1980, 2000, and 2008 (Fig. 1 in Supplementary Material), we used a set of biophysical models to simulate four key ecosystem services in the Yanhe Basin. From a 1:50000 scale DEM map $(25 \times 25 \mathrm{~m})$ from the National Geomatics Center of China, the entire Yanhe Basin was divided into 35 sub-basins, and model calculations performed at $25-\mathrm{m}$ resolution. Along the Yanhe River, 35 subbasins are cataloged according to the Strahler classification (Fig. 2 in Supplementary Material).

The formulas for modeling ecosystem services and the correlation and correspondence analyses are described below:

\section{Soil conservation $(\mathrm{SC})$}

The calculation of the Soil Conservation Service is represented by the difference between potential soil loss and the actual amount of soil erosion (Renard et al. 1997).

Potential soil erosion (RKLS):

$R K \mathrm{LS}=R \cdot K \cdot \mathrm{LS}$

where $R$ is the rainfall erosive factor $(\mathrm{MJ} * \mathrm{~m} / \mathrm{ha} * \mathrm{~h})$, $K$ is the factor of soil erodibility (Fu et al. 2005), and LS is the factor of slope length and slope gradient (Zhou and Liu 2006).

Actual soil erosion is estimated by the Universal Soil Loss Equation (USLE):

$\mathrm{USLE}=R \cdot K \cdot \mathrm{LS} \cdot P \cdot C$

where $P$ is the factor of vegetation coverage and $C$ is the factor of engineering measures (Fu et al. 2005).

Ecosystem service for soil conservation (SC):

$\mathrm{SC}=R K \mathrm{LS}-\mathrm{USLE}=R \cdot K \cdot \mathrm{LS} \cdot(1-P C)$

Water yield (WY)

The water yield model is based on the Budyko assumption and annual average precipitation (Budyko 1974):

$\mathrm{WY}=\sum_{i}\left(1-\frac{\mathrm{AET}_{k i}}{P_{i}}\right) \cdot P_{i}$ where $\mathrm{AET}_{k i}$ is the actual annual evapotranspiration on pixel $i$ with land-use type $k$, and $P_{i}$ is the precipitation for pixel $i$.

$\frac{\mathrm{AET}_{k i}}{P_{i}}=\frac{1+\omega_{i} R_{i k}}{1+\omega_{i} R_{i k}+\frac{1}{R_{i k}}}$

where $R_{i k}$ is the Budyko dryness index on pixel $i$ with land-use type $k$, defined as the ratio of potential evapotranspiration and precipitation, and $\omega_{i}$ are the parameters for the description of natural climate and soil properties, defined as the ratio of annual water demand for plants and precipitation (Zhang et al. 2001).

$R_{i k}=\frac{k \cdot E T_{0}}{P_{i}}$

where $k$ is the coefficient of vegetation transpiration and $\mathrm{ET}_{0}$ is the potential evapotranspiration. $k$ values vary from 0.3 (Build up areas) to 1.0 (Woodlands).

$\omega_{i}=Z \frac{\mathrm{AWC}_{i}}{P_{i}}$

where $\mathrm{AWC}_{i}$ is the volumetric (mm) water content available for plants and $\mathrm{Z}$ is a seasonality factor that represents the seasonal rainfall distribution and rainfall depths, ranging from 1 to 10,10 for areas of winter rains and 1 for regions with summer rains or humid areas with rain events distributed throughout the year. In our study area, we set it to 2, according to the InVEST User's Guide.

Water retention (WR)

The formula for the water retention model ( $\mathrm{Yu}$ et al. 2012) is as follows:

$$
\begin{aligned}
\mathrm{WR}= & \operatorname{Min}\left(1, \frac{249}{\text { Velocity }}\right) * \operatorname{Min}(1,0.3 \mathrm{TI}) \\
& * \operatorname{Min}\left(1, \frac{K_{\text {sat }}}{300}\right) * \mathrm{WY}
\end{aligned}
$$

where Velocity is the flow coefficient, TI is the topographic index, and $K_{\text {sat }}$ is the soil saturated hydraulic conductivity.

Crop production $(\mathrm{CP})$

The formula for the crop production model is:

$\mathrm{CP}=P_{\mathrm{v}} * I_{\mathrm{zrd}}$ 
where $P_{\mathrm{v}}$ is the climatic productivity for a crop (Wu et al. 2008) and $I_{\mathrm{zrd}}$ is the land-use level index, which is determined by the regulations of farm land grading in China.

$P_{v}=30000\left(1-\mathrm{e}^{-0.000956(v-20)}\right)$

where $v$ is the average annual evapotranspiration.

Correlation and correspondence analysis

The correlation coefficient for each pair of ecosystem services is calculated by Arcgis software (ArcGIS 9.3) at a pixel scale; meanwhile, the correlation analysis between the amounts of changes in ecosystem services is also carried out.

The correspondence analysis is performed to explore the relationship of ecosystem services with land-use types and ecosystem services with sub-basins (Hill 1974). For the entire basin, the average value of each ecosystem service on each kind of land-use type or on each sub-basin is calculated. In order to make average values comparable in a contingency table, on which the correspondence analysis is performed, the numbers are standardized by the formula as follows:

$x_{i j}^{\prime}=\frac{x_{i j}}{\max \left(x_{\cdot j}\right)}$

where $x_{i j}$ is the average value of ecosystem service $j$ on land-use type $i$ or sub-basin $i, \max \left(x_{. j}\right)$ is the max value among the average values of ecosystem service $j$ on all kinds of land-use types or all sub-basins. The result of the correspondence analysis is displayed in a twodimensional graph.

\section{Results}

Ecosystem services evaluation

The spatial distributions of the four ecosystem services in the Yanhe Basin are displayed (Figs. 3, 4, 5 , and 6 in Supplementary Material). There is no significant difference in ecosystem services between 1980 and 2000, due to the absence of the GGP. From 2000 to 2008, for the entire basin, two ecosystem services (soil conservation and water retention) have been improved by returning farm land to forest land and grass land, but the other two ecosystem services (water yield and crop production) appear to have a tendency to decrease. All kinds of ecosystem services have increased from northwest to southeast in various years.

Spatial correlations between ecosystem services

Soil conservation was negatively correlated with water yield/crop production but positively correlated with water retention (Table 1, in Supplementary Material). Water retention has a positive correlation with water yield but a negative correlation with crop production. There is a negative correlation between water yield and crop production. Although the correlation symbols (positive or negative) are the same for both the status quo and the differences between two individual years, the value of the correlation coefficient differs considerably. For example, the correlation coefficient between soil conservation and water yield for 1980-2000 (2000-2008 or 1980-2008) is much lower than the coefficient in 1980 (or 2000 or 2008).

The correlation coefficient for a given year represents the differences in the spatial distribution of two ecosystem services and the accompanying effects as a result of environmental gradients such as rainfall or different spatial patterns of vegetation and land use, reflecting a static corresponding relationship, and the positive sign indicates that the spatial distribution is consistent for two different ecosystem services, only meaning that both ecosystem services display a higher or lower value at the same time. The correlation coefficient for a given period represents the interaction between two ecosystem services and the possible causal effects as a general result of land use/land cover (LULC) and climate change, reflecting the dynamic interactive relationship, and the positive sign indicates that two ecosystem services change in the same direction and that synergy may exist between two ecosystem services. This is why the relatively large gap exists between the correlation coefficients of the status quo and the differences between two individual years (Table 1, in Supplementary Material).

Correspondence analysis between land-use types and ecosystem services

There are various strengths for forest, shrub, grass, and farm land to providing ecosystem services. The forest 
land points (80_fo, 00_fo, 08_fo) and the farm land points (80_fa, 00_fa, 08_fa) are far from each other (Fig. 7 in Supplementary Material) because their natural characteristics are significantly different, reflecting the maximum difference in the degree of human intervention among different land-use types. However, the grass land points are close to the shrub land points (80_sh, 00_sh, 08_sh) because their water and soil conservation service functions are similar. From farm land points to forest land points, roughly from the left side (positive) to the right side (negative) of the origin for the first dimension, there is an increasing trend for soil and water conservation services. It shows that the first dimension distinguishes largely between the different degrees of the losses of water and soil. The ecosystem service points nearest from forest land points are soil conservation points (SC). This denotes that the main ecosystem service for forest land is soil conservation; in other words, forest should mainly be used to keep the soil, rather than for other purposes.

Correspondence analysis between sub-basins and ecosystem services

In 1980, 2000, and 2008, the C_S point, reflecting the capacity of crop production in a sub-basin, is always located on the right side of the origin for the first dimension, while SC and WR points, reflecting soil and water conservation, lie on the left side (Fig. 8a-c, in Supplementary Material). According to the distribution of ecosystem service points, it appears that there is a gradual transition of the main ecosystem service across the sub-basins, changed from provision services to regulating services, from the right side to the left side of the origin for the first dimension. The third quadrant seems to be a concentrated area of soil and water conservation services. Most of the subbasins (1-M, 1-O, 1-Q, 1-R, 3-A) that are close to the points of the water retention and soil conservation are located in the regions of downstream or high-level reaches. The sub-basin, far away from the soil conservation and water retention, is prone to appear in the regions of upstream and low-level reaches. The sub-basin points, around the C_S and C_A points, are approximately distributed in the high-level reaches, which suggest that there may be good irrigation conditions and relatively enough water for crop production. The sub-basins of high crop yield per unit area (close to the C_A point) do not coincide with the sub-basins of high total crop yield (close to the C_S point).

\section{Discussion}

The relationships among ecosystem services

The relationships among ecosystem services are divided into tradeoff and synergy. Both of these are due to simultaneous responses to the same driver or the true interactions among ecosystem services (Bennett et al. 2009) and they indicate the relationship between the changes of ecosystem services and not between static ecosystem services. A tradeoff is a shift in the process similar to a zero-sum game and while increasing a kind of ecosystem service, another one declines. Tradeoff usually occurs between provisioning services and both regulating and cultural services, such as pork production and tourism (Raudsepp-Hearne et al. 2010), wood supply and carbon storage, and food supply and water purification (Joseph et al. 2003). Synergy is a win-win process in which two kinds of ecosystem services increase; for instance, surface water quality and soil retention, pasture production, and freshwater supply (Qiu and Turner 2013). As a general result of the correlation analysis, the coefficient value for a tradeoff relationship is shown as negative and the synergy is positive (Chan et al. 2006; Egoh et al. 2009; Butler et al. 2013). Although the correlation analysis provides a relatively concise and explicit method for judging the potential tradeoffs and synergies, the specific application process still requires attention.

Two types of potential errors exist when exploring the relationship between ecosystem services through spatial correlation. The first type of potential error is to identify the relationship between ecosystem services by using the correlation coefficient in a given year, ignoring the prerequisites of dynamic nature and true interaction when considering the tradeoff or synergy. Using a relatively large unit of stats is the second type of potential error to determine whether there is a tradeoff or synergy. For instance, the grassland is split into two blocks with the same size and is converted into forest land and residential land, separately. Whether it is the transformation from grass land to forest land or grass land to residential land, both water retention and soil conservation change in the same 
direction, simultaneously increasing in forest land and decreasing in residential land, and appears as a synergy in line with normal logic if considering a forest land or residential land block to be a unit of stats. When all of the grass land are set into one unit of stats and the magnitudes of the changes are not the same for the two blocks, for example, the loss of water retention in the residential block is much higher than the gain of the forest land block; meanwhile, the gained soil conservation in the forest land block exceeds the loss of the residential land and the calculated result shows that the water retention is decreasing while the soil conservation is increasing. The relationship for ecosystem services would probably be displayed as tradeoff for the whole grass land, like the tradeoff between ecosystem services at a national scale (Dymond et al. 2012). The second type of potential error comes from ignoring the prerequisite of the same driver in a geographical statistical unit when using a correlation analysis; for example, the same land-use change occurs.

The correlation coefficient signifies the changes in ecosystem services across time and the geographical statistical unit is as small as possible (Seppelt et al. 2011), which are the prerequisites for correctly identifying the tradeoff or synergy. In this study area, the spatial correlation was carried out on a pixel scale $(25 \times 25 \mathrm{~m})$, which is sufficiently small enough to limit only one type of land-use change in a geographical statistical unit, ensuring the same driver. According to the correlation coefficients in 1980-2000, 2000-2008, and 1980-2008 (Table 1, in Supplementary Material), which were considered to be dynamic interactions, it is indicated that there is probably a synergy between soil conservation and water retention, and water yield shows a tradeoff with soil conservation and a synergy with water retention in the Yanhe Basin from 1980 to 2008.

The relationship between land use and ecosystem services over time

Linkages between land-use change and ecosystem services can be one-to-many, many-to-one, and manyto-many (Bryan 2013). Therefore, the discussion on the relationship between land-use type and ecosystem services could help us to understand the role of landuse change in the interactions among ecosystem services (Lautenbach et al. 2011; Schneiders et al. 2012; Chen et al. 2013; Sawut et al. 2013; Su and Fu 2013). Different land-use types can produce the same kinds of ecosystem services. For example, both forest land and grass land could generate the benefit of soil conservation and water retention, but their closeness to soil conservation and water retention is inconsistent; moreover, the closeness may change over time. The distances between the landuse points and ecosystem service points did not change from 1980 to 2000, but they did change from 2000 to 2008, for most of the land-use points. For example, points of 08_fa, 08_sh are beginning to depart from 80_fa and 00_fa, 80_sh and 00_sh separately (Fig. 7 in Supplementary Material), meaning that the GGP changed the intensities of the ecosystem services provided by farm land or shrub land. Whether this tendency would be maintained is worthy of further study. The distances from the shrub land and grass land points to the soil conservation/water retention points are relatively short, suggesting that shrub lands and grass lands could very well meet the purposes of soil conservation and water retention at the same time in the Yanhe Basin. This proves the correctness of the measures taken by GGP, which mainly rely on planting shrubs and grasses to restore ecosystem services.

The relationship between sub-basin and ecosystem services over time

Spatial location and scale play important roles in valued ecosystem services, especially regulating services, because stakeholders at different spatial scales assign different values to ecosystem services (Hein et al. 2006). Displaying the changes in the spatial layouts of the ecosystem services is helpful for further improvement of landscape design (Jones et al. 2013). Hence, it is necessary to appropriately analyze the varieties and relationships between ecosystem services and their spatial information (Qiu and Turner 2013; Serna-Chavez et al. 2014). There is no apparent distinction between plots from 1980 to 2000 (Fig. 8a, $\mathrm{b}$, in Supplementary Material). This suggests that the relationships between ecosystem services and the subbasins are substantially maintained in the original state over 1980-2000. However, there is a trend to move left and away from C_S point during 2000-2008, especially for the sub-basins close to C_S point in 2000, for example, points of 1-G, 2-A, 2-B, and 3-B (Fig. 8b, c, in Supplementary Material). For a subbasin, it shows that the internal proportion of 
regulating service to provision service has been changed by GGP. For the entire Yanhe Basin, the GGP has still not changed the relative spatial patterns of the ecosystem services, though ecosystem services have been improved significantly throughout the entire study area (Figs. 3, 4, 5, and 6 in Supplementary Material). Because, in a comparison of the regions in upstream and low-level reaches, the regions of downstream and high-level reaches still have higher values in water retention, soil conservation, water yield, and crop production, in despite of 1980, 2000, or 2008. Briefly, GGP has changed the internal structure of ecosystem service in a single sub-basin, but has not changed the relative spatial patterns for a single kind of ecosystem service in the whole study area.

\section{Conclusions}

Using various biophysical models, we calculated four ecosystem services (soil conservation, water retention, water yield, and crop production) in the Yanhe Basin. We applied spatial correlation to analyze the relationships between ecosystem services and proposed two preconditions for the analysis process. The results showed that there was synergy between soil conservation and water retention. Water yield showed a tradeoff with soil conservation and synergy with water retention in the Yanhe Basin from 1980 to 2008. The correspondence analysis was used to explore the intrinsic linkages between ecosystem services and land use/sub-basins. GGP has changed the intensities of the ecosystem services provided by most of land uses. In the study area, the internal proportion of regulating service to provision service in a sub-basin has been changed, but the relative spatial patterns of ecosystem services in the basin scale are still being maintained from 1980 to 2008 .

Acknowledgments This work was funded by the National Natural Sciences Foundation of China (No. 41230745).

\section{References}

Bennett EM, Peterson GD, Gordon LJ (2009) Understanding relationships among multiple ecosystem services. Ecol Lett 12:1394-1404

Bryan BA (2013) Incentives, land use, and ecosystem services: synthesizing complex linkages. Environ Sci Policy 27:124-134
Budyko MI (1974) Climate and life. Academic Press, San Diego, California

Butler JRA, Wong GY, Metcalfe DJ, Honzak M, Pert PL, Rao $\mathrm{N}$, van Grieken ME, Lawson T, Bruce C, Kroon FJ, Brodie JE (2013) An analysis of trade-offs between multiple ecosystem services and stakeholders linked to land use and water quality management in the Great Barrier Reef, Australia. Agric Ecosyst Environ 180:176-191

Cao SX, Chen L, Yu XX (2009) Impact of China's Grain for Green Project on the landscape of vulnerable arid and semiarid agricultural regions: a case study in northern Shaanxi Province. J Appl Ecol 46:536-543

Chan KMA, Shaw MR, Cameron DR, Underwood EC, Daily GC (2006) Conservation planning for ecosystem services. PLoS Biol 4:2138-2152

Chen LD, Wei W, Fu BJ, Lu YH (2007) Soil and water conservation on the Loess Plateau in China: review and perspective. Prog Phys Geogr 31:389-403

Chen LD, Yang L, Wei W, Wang ZT, Mo BR, Cai GJ (2013) Towards sustainable integrated watershed ecosystem management: a case study in Dingxi on the Loess Plateau, China. Environ Manag 51:126-137

Costanza R, d'Arge R, deGroot R, Farber S, Grasso M, Hannon B, Limburg K, Naeem S, Oneill RV, Paruelo J, Raskin RG, Sutton P, van den Belt M (1997) The value of the world's ecosystem services and natural capital. Nature 387:253-260

Cowie AL, Penman TD, Gorissen L, Winslow MD, Lehmann J, Tyrrell TD, Twomlow S, Wilkes A, Lal R, Jones JW, Paulsch A, Kellner K, Akhtar-Schuster M (2011) Towards sustainable land management in the drylands: scientific connections in monitoring and assessing dryland degradation, climate change and biodiversity. Land Degrad Dev 22:248-260

Daily GC (1997) Nature's services: societal dependence on natural ecosystems. Island Press, Washington, DC

Daily GC, Polasky S, Goldstein J, Kareiva PM, Mooney HA, Pejchar L, Ricketts TH, Salzman J, Shallenberger R (2009) Ecosystem services in decision making: time to deliver. Front Ecol Environ 7:21-28

Dymond JR, Ausseil A-GE, Ekanayake JC, Kirschbaum MUF (2012) Tradeoffs between soil, water, and carbon-a national scale analysis from New Zealand. J Environ Manag 95:124-131

Egoh B, Reyers B, Rouget M, Bode M, Richardson DM (2009) Spatial congruence between biodiversity and ecosystem services in South Africa. Biol Conserv 142:553-562

Foley JA, DeFries R, Asner GP, Barford C, Bonan G, Carpenter SR, Chapin FS, Coe MT, Daily GC, Gibbs HK, Helkowski JH, Holloway T, Howard EA, Kucharik CJ, Monfreda C, Patz JA, Prentice IC, Ramankutty N, Snyder PK (2005) Global consequences of land use. Science 309:570-574

Fu BJ, Zhao WW, Chen LD, Zhang QJ, Lu YH, Gulinck H, Poesen J (2005) Assessment of soil erosion at large watershed scale using RUSLE and GIS: a case study in the Loess Plateau of China. Land Degrad Dev 16:73-85

Fu BJ, Liu Y, Lu YH, He CS, Zeng Y, Wu BF (2011) Assessing the soil erosion control service of ecosystems change in the Loess Plateau of China. Ecol Complex 8:284-293

Goldstein JH, Caldarone G, Duarte TK, Ennaanay D, Hannahs N, Mendoza G, Polasky S, Wolny S, Daily GC (2012) 
Integrating ecosystem-service tradeoffs into land-use decisions. Proc Natl Acad Sci USA 109:7565-7570

Hein L, van Koppen K, de Groot RS, van Ierland EC (2006) Spatial scales, stakeholders and the valuation of ecosystem services. Ecol Econ 57:209-228

Hill MO (1974) Correspondence analysis: a neglected multivariate method. journal of the royal statistical society. Ser C (Appl Stat) 23:340-354

Jones KB, Zurlini G, Kienast F, Petrosillo I, Edwards T, Wade TG, Li BL, Zaccarelli N (2013) Informing landscape planning and design for sustaining ecosystem services from existing spatial patterns and knowledge. Landscape Ecol 28:1175-1192

Joseph A et al (2005) Millenium ecosystem assessment. In: Ecosystems and human well-being: a framework for assessment. Island Press, Washington, DC

Lautenbach S, Kugel C, Lausch A, Seppelt R (2011) Analysis of historic changes in regional ecosystem service provisioning using land use data. Ecol Ind 11:676-687

Lu YH, Fu BJ, Feng XM, Zeng Y, Liu Y, Chang RY, Sun G, Wu BF (2012) A policy-driven large scale ecological restoration: quantifying ecosystem services changes in the Loess Plateau of China. PloS One 7(2):e31782

Martinez ML, Perez-Maqueo O, Vazquez G, Castillo-Campos G, Garcia-Franco J, Mehltreter K, Equihua M, Landgrave R (2009) Effects of land use change on biodiversity and ecosystem services in tropical montane cloud forests of Mexico. For Ecol Manag 258:1856-1863

Nelson E, Mendoza G, Regetz J, Polasky S, Tallis H, Cameron DR, Chan KMA, Daily GC, Goldstein J, Kareiva PM, Lonsdorf E, Naidoo R, Ricketts TH, Shaw MR (2009) Modeling multiple ecosystem services, biodiversity conservation, commodity production, and tradeoffs at landscape scales. Front Ecol Environ 7:4-11

Power AG (2010) Ecosystem services and agriculture: tradeoffs and synergies. Philos Trans R Soc B Biol Sci 365:2959-2971

Qiu J, Turner MG (2013) Spatial interactions among ecosystem services in an urbanizing agricultural watershed. Proc Natl Acad Sci USA 110:12149-12154

Raudsepp-Hearne C, Peterson GD, Bennett EM (2010) Ecosystem service bundles for analyzing tradeoffs in diverse landscapes. Proc Natl Acad Sci USA 107:5242-5247

Renard KG, Foster GR, Weesies GA, McCool DK, Yoder DC (1997) Predicting soil erosion by water: a guide to conservation planning with the revised universal soil loss equation (RUSLE). United States Government Printing Office, Washington, DC
Rodrigues RR, Gandolfi S, Nave AG, Aronson J, Barreto TE, Vidal CY, Brancalion PHS (2011) Large-scale ecological restoration of high-diversity tropical forests in SE Brazil. For Ecol Manag 261:1605-1613

Sawut M, Eziz M, Tiyip T (2013) The effects of land-use change on ecosystem service value of desert oasis: a case study in Ugan-Kuqa River Delta Oasis, China. Can J Soil Sci 93:99-108

Schneiders A, Van Daele T, Van Landuyt W, Van Reeth W (2012) Biodiversity and ecosystem services: complementary approaches for ecosystem management? Ecol Ind 21:123-133

Seppelt R, Dormann CF, Eppink FV, Lautenbach S, Schmidt S (2011) A quantitative review of ecosystem service studies: approaches, shortcomings and the road ahead. J Appl Ecol 48:630-636

Serna-Chavez HM, Schulp CJE, van Bodegom PM, Bouten W, Verburg PH, Davidson MD (2014) A quantitative framework for assessing spatial flows of ecosystem services. Ecol Ind 39:24-33

Su CH, Fu BJ (2013) Evolution of ecosystem services in the Chinese Loess Plateau under climatic and land use changes. Glob Planet Change 101:119-128

Su CH, Fu BJ, Wei YP, Lu YH, Liu GH, Wang DL, Mao KB, Feng XM (2012) Ecosystem management based on ecosystem services and human activities: a case study in the Yanhe watershed. Sustain Sci 7:17-32

Tallis H, Kareiva P, Marvier M, Chang A (2008) An ecosystem services framework to support both practical conservation and economic development. Proc Natl Acad Sci USA 105:9457-9464

Wu BF, Xong J, Yan NN, Yang LD, Du X (2008) ETWatch for monitoring regional evapotranspiration with remote sensing. Adv Water Sci 19:671-678 (in Chinese)

Wu J, Feng Z, Gao Y, Peng J (2013) Hotspot and relationship identification in multiple landscape services: a case study on an area with intensive human activities. Ecol Ind 29:529-537

Yu XL, Zhou B, Lu XZ, Yang ZG (2012) Evaluation of water conservation function in mountain forest areas of Beijing based on InVEST model. Sci Silvae Sin 10:1-5 (in Chinese)

Zhang L, Dawes WR, Walker GR (2001) Response of mean annual evapotranspiration to vegetation changes at catchment scale. Water Resour Res 37:701-708

Zhou Q, Liu X (2006) Digital topography analysis. Science Press, Beijing 